\title{
PHILOLOGY
}

\section{ОБУЧЕНИЕ ИНОСТРАННЫХ СТУДЕНТОВ КОМПРЕССИИ НАУЧНОГО ТЕКСТА}

\author{
Дочент, к.ф.н. Мусабекова Н. Ч. \\ Азербайджанская Республика, Баку, \\ Азербайджсанский государственный университет нефти и промышленности
}

DOI: https://doi.org/10.31435/rsglobal_wos/31032019/6393

\section{ARTICLE INFO}

Received: 27 January 2019

Accepted: 22 March 2019

Published: 31 March 2019

\section{KEYWORDS}

compression of scientific texts, genres of compression. \begin{abstract}
The study was aimed to consider different ways and genres of the compression of scientific texts. Author notes the specificity of acquisition of the compression skills by foreign students, draws attention to the stages of work on the transformation of original texts into "derivative texts" according to the ultimate goal. Author calls for greater emphasis on training on drawing up different types of plans, taking notes for scientific literature and lectures, writing of annotations and reviews, compiling thesis on different subjects and etc. Author provides valuable recommendations in organization and work with students and masters on the development their skills at different degrees of original text compression. The article acknowledges that training classes in the compression of scientific texts are very important for the development of students' communication skills.
\end{abstract}

Citation: Мусабекова Н. Ч. (2019) Obuchenie Inostrannyh Studentov Kompressii Nauchnogo Teksta. International Academy Journal Web of Scholar. 3(33). doi: 10.31435/rsglobal_wos/31032019/6393

Copyright: (C) 2019 Мусабекова Н. Ч. This is an open-access article distributed under the terms of the Creative Commons Attribution License (CC BY). The use, distribution or reproduction in other forums is permitted, provided the original author(s) or licensor are credited and that the original publication in this journal is cited, in accordance with accepted academic practice. No use, distribution or reproduction is permitted which does not comply with these terms.

Введение. Большая часть иностранных студентов, приезжающая в Азербайджан с целью получения высшего образования в вузах страны, испытывают трудности в освоении научного стиля речи русского языка.

В настоящей статье мы хотим остановиться лишь на одном аспекте проблемы обучения иностранных студентов языку специальности, а именно: на проблеме трансформации информативного содержания научного текста, жанрах "вторичных текстов" и обучении студентов способам компрессии текста по специальности.

Результат исследования. Компрессия - это основной вид переработки текста. На основе определенных манипуляций с текстом-оригиналом можно составить новый, "вторичный" текст, в различных жанрах: план, аннотация, тезисы, реферат, резюме и т.д. В процессе компрессии исходного текста мы лучше осознаем смысловую и композиционную структуру текста-первоисточника, выделяем наиболее важные моменты в его содержании, вычленяем основную и второстепенную информацию. Умение производить смысловое сжатие текста в соответствии с поставленной целью весьма важно на стадии подготовки студентов и магистров начального этапа обучения, т.к. в дальнейшем им придется самим составлять тезисы, писать рефераты, аннотации, рецензии, а также курсовые и дипломные работы.

Отметим главные принципы, являющиеся основой компрессии текста и коими должны руководствоваться студенты в процессе работы над научным текстом:

1) внимательное чтение текста-первоисточника и выделение в нем ключевых слов и предложений, содержащих основной смысл высказывания. Последнее невозможно без 
понимания строения абзацев текста, которые включают введение в проблему, основную часть (комментарий) и вывод;

2) собственно написание "вторичного" текста с использованием стандартных речевых оборотов (клише),

а) выражающих позицию автора по отношению к тексту-первоисточнику (Например: Статья представляет собой..,; в работе исследуется..; в диссертации использованьь следуюшие методы исследования... и др.);

б) отражающих композицию текста-первоисточника (Например: Bo-nеpвых, aвтор...; во втором параграфе сообщается... и др.);

в) передающих основное содержание текста-оригинала (Например: Aвтор доказывает...; автор ссылается на...; исследователь приводит примеры (факты)...; опираясь на точку зрения..., автор доказывает... и др.);

г) характеризующих/оценивающих суть содержания отдельных параграфов/ положений текста-оригинала и всего текста-первоисточника в целом (Например: В монографии освещаются...; автор уделяет внимание тому, что...;; авторы высказывают предположение, что... и др.(полная оценка содержания текста) ИЛИ В статье затрагиваются вопросы...;; автор упоминает....; автор перечисляет....и др. (частичная оценка содержания текста) ИЛИ В публикации подчёркивается, что...; автор указывает на важность того, что...; автор обращает внимание на то, что...; автор имеет в виду, что... и др. (выделение конкретной мысли) ИЛИ Автор считает, что...; автор замищает....; автор отстаивает точку зрения... ; автор убеждает в том, что.... (высказывание точки зрения) ИЛИ Автор разделяет точку зрения...; автор критикует...; в статье разоблачается...; в публикации опровергается... и др. (выражение оценки)) [1]

Таким образом, в процессе компрессии текста-источника студент, с одной стороны, проводит структурно-смысловой анализ текста, с другой стороны, комбинируя и комментируя его, он трансформирует содержание текста в соответствии с коммуникативными задачами в план, тезисы, конспект и т.д.

Первый вид компрессии текста, с которым студент знакомится на уроках по научному стилю речи уже в первом семестре, - это план.

План - самый короткий вид (кроме заголовка) трансформации первичного текста. План четко отражает последовательность изложения мыслей, заложенных в научном тексте, помогает лучше понять и запомнить прочитанный материал. Работа над планом текста позволяет соотнести содержание и композицию текста, вскрыть структурные и смысловые отношения между фрагментами текста и тем самым лучше организовать устное выступление или письменное высказывание на заданную тему. План является одним из средств самоконтроля и самооценки учащихся.

Работа над планом предполагает следующие стадии работы:

1) осмысление учащимися основной темы текста;

2) определение микротем и их последовательности в исходном тексте;

3) осмысление заголовка текста (или предложение собственного названия), т. к. в заголовке в предельно сжатой форме передается основное смысловое содержание текста; заголовок является высшим уровнем компрессии текста.

Под руководством преподавателя студенты вначале составляют вопросный план, а потом трансформируют его в простой или развёрнутый (в зависимости от сложности содержания и структуры) назывной план. Имея опыт постановки вопросов к отдельным членам предложения и фрагментам текста нейтрального стиля речи, студенты, как правило, не испытывают трудностей с постановкой специальных вопросов, начинающихся с вопросительных слов "где, когда, почему, какой" и др. А зная, что количество пунктов и подпунктов плана обычно соответствует количеству абзацев текста-оригинала, учащиеся достаточно быстро добиваются успеха в составлении краткого (или подробного) вопросного плана. Сложнее дело обстоит с составлением назывного плана, т. к., с одной стороны, студент-иностранец должен фиксировать в памяти информативные центры каждого абзаца текста, а с другой стороны, формулировать заглавие каждого пункта плана в форме назывного предложения. Т.е. студент должен овладеть способами компрессии предложений без потери смысла и техникой трансформации глагольных сочетаний (чаще всего типа: глагол "действие" + сущ. в В.п.) в именные (чаще всего типа: сущ. "процесс" + сущ. в Р.п.), двусоставных предложений - в односоставные назывные. Подобного рода трансформации лучше всего отработать в процессе выполнения предтекстовых заданий. 
На первом этапе можно остановиться на составлении краткого назывного плана, позже развернуть его до уровня сложного плана (план-тезисы), в котором отдельные параграфы представляют собой 1-2 двусоставных предложения, передающих основную тему текста и детализирующих ее, вычленяя в ней подтемы.

Раскрывая пункты сложного плана, с опорой на текст-оригинал, студент позже сможет самостоятельно написать подробный конспект текста.

Другим, более сложным, видом компрессии научного текста являются тезисы. Студентам очень важно освоить тезирование текста, т. к. это является шагом к конспектированию. Тезисы отражают основные положения абзацев учебного текста, текста лекции, доклада. В процессе тезирования студенты учатся делить текст на смысловые части, выявлять основную информацию каждого фрагмента текста, а затем обобщать ее в виде1-3 предложений. Студентам предстоит освоить составление вторичных и оригинальных тезисов.

Bторичные тезисы ставят своей целью выделить главную информацию, содержащуюся в конкретной научной статье, учебнике и др. источнике. Оригинальные же mезисы являются первичным текстом и представляют собой минитекст предстоящего выступления на семинаре, презентации, конференции и т.п. Они сформулированы двусоставными предложениями, раскрывающими содержание микротем, и публикуются в специальных сборниках. Научную деятельность студентов, магистров, аспирантов не возможно представить без такого вида работы, как тезирование учебной и научной литературы.

Конспектирование литературы по специальности также является составной частью учебной и научной подготовки молодых специалистов. С первых же дней учебы в университете/магистратуре студенту/магистру приходится конспектировать тексты по специальности и составлять конспекты лекций. Часто под конспектом учащиеся подразумевает любую краткую запись содержания текста (порой - механическое сокращение текста), что, конечно, является ошибочным. Поэтому студенту необходимо разъяснить, что конспект должен представлять собой связный рассказ, в котором повествование должно соответствовать внутренней логике автора первичного текста. При всей своей обязательной краткости конспект должен содержать не только положения и выводы, но и факты, примеры, доказательства, иллюстрирующие позицию автора текста-оригинала. [3, 51-52] Таким образом, мы подошли к решению проблемы, как собственно писать конспект. Составлению конспекта должна предшествовать подготовительная работа:

а) осмысление основной темы и задач текста;

б) предварительное составление подробного плана текста в виде расширенных тезисов;

в) отбор необходимого иллюстративного материала (факты, примеры, цитаты, схемы, рисунки...), который будет раскрывать отдельные положения конспекта;

г) оформление библиографии;

д) собственно составление конспекта, который должен обязательно содержать введение, основную (центральную) часть, выводы и заключение; названные части должны быть дополнены списком использованной литературы, иногда - приложением и иллюстративным материалом.

В связи со сказанным становится понятно, что одной из составляющих работы по обучению студентов/магистров конспектированию является их обучение правильному оформлению цитат, библиографии, правильному сокращению слов, использованию общепринятых сокращений, знаков и разработке своей собственной системы условных знаков и аббревиатур на языке обучения и т.п.

Отбор, переработка и фиксирование на письме информации - личностный процесс: разные люди по-разному оценивают и отображают информацию, поэтому текст, восстановленный по конспектам разных людей, может достаточно сильно отличаться. Студенты также должны усвоить, что содержание конспекта лучше усваивается и визуально лучше выглядит, если составитель вторичного текста выделяет заголовки тем и подтем, термины, формулы и другую важную информацию разными по форме и цвету шрифтами, подчеркиванием, символами и т.п.

Итак, мы рассмотрели алгоритм составления конспекта научного текста, но студентам приходится составлять и собственные конспекты лекций, хотя все более и более популярным становится помещение преподавателями-лекторами на специальных сайтах вузов электронных 
версий лекций по всем предметам. Некоторые учащиеся довольствуются этими текстами, не учитывая того факта, что краткий текст лекции в 3-5 страниц не может полностью охватить все проблемы и нюансы, освещаемые лектором в "звучащей", "живой" лекции. Поэтому на уровне подготовительного факультета необходимо уделить внимание вопросам записи лекции со слуха.

Конспектирование лекции - это творческий процесс, в котором задействованы преподаватель и учащийся. Слушая лекцию, иностранный студент должен "ухватить" узловые моменты лекции, переработать их в уме (перевести отдельные положения на родной язык), отобрать нужную информацию и, используя навыки скорописи, записать основные положения лекции в тетрадь. Обучая студентов записи лекции, преподаватель должен обратить внимание студентов на несколько моментов:

а) в тетрадях для записи лекций должны быть поля для дополнений и замечаний;

б) нужно обращать внимание не только на содержание лекции, но и на интонацию, темп речи лектора, что помогает вычленить и записать ключевую информацию;

в) овладевая общепринятыми правилами сокращения слов и системой общепринятых символов, студенту необходимо выработать свою собственную систему символов и аббревиатур;

г) обязательными для внесения в конспект являются схемы, таблицы и т.д., которые демонстрируются лектором в процессе лекции;

д) после окончания лекции необходимо выверить текст конспекта, уточнить термины, определения явлений, выводы и т.П., прояснить все вопросы, возникшие по ходу лекции и др.

Другим важным видом компрессии текста, который должен быть освоен студентом, является реферат. Он близок тематическому конспекту, составленному по нескольким источникам. В тематическом конспекте обеспечивается единство содержания, логическая и грамматическая связь между отдельными фрагментами, наличествует иллюстративный материал, четко прослеживается система аргументов и доказательств автора оригинального текста. Но если в peферате представлена только точка зрения автора, то в консnекте учащийся выражает собственное мнение по затрагиваемым проблемам, по-своему интерпретируя почерпнутую информацию и критически оценивая позицию автора/авторов оригинального/ых текста/ов.

Peфepambl можно классифицировать по группам по разным параметрам (содержанию, количеству реферируемых источников, читательскому назначению и т.п.). Особый интерес для студентов и магистров представляют репродуктивные (воспроизводят содержание текстапервоисточника) и продуктивные (предполагают творческое осмысление реферируемых источников), т. к. умение их составлять поможет в дальнейшем при написании курсовых и дипломных работ.

К репродуктивным относят: а) реферат-конспект, в котором содержится общая фактическая информация, иллюстративный материал, сведения о полученных результатах и сферах их применения; б) реферат-резюме, в котором основные положения исследования представлены в виде общих выводов по результатам научной работы.

К продуктивным относят: a) реферат-обзор, в котором охватывается тематика и основное содержание нескольких первоисточников, сопоставляются точки зрения разных авторов по конкретному вопросу; б) реферат-доклад, в котором дается анализ информации, приведенный в первоисточниках и объективная оценка состояния изучаемой проблемы.

Объем реферата составляет 15-30\% реферируемой работы. В структуре реферата выделяются 3 компонента: собственно реферативный текст, библиография и справочный аппарат.

Обучение компрессии научного текста предполагает и обучение правильному составлению аннотаций к первоисточнику. Правильное написание аннотации достаточно сложное дело. По сути, аннотация является развернутым заголовком текста. В ней в краткой форме передается концепция текста/книги, тип и назначение научного труда, задачи, поставленные автором; отражается метод исследования; принадлежность автора к определенной научной школе или направлению; даются указания на структуру, тему, предмет исследования, основные положения и выводы автора; указания на вспомогательный и иллюстративный материал. Подготовив совместно со студентами вариант аннотации к статье/книге/учебному пособию, можно затем предложить учащимся составить собственный вариант аннотации к используемому учебному пособию, в котором учащийся должен обязательно дать краткую характеристику основной темы, осветить основные вопросы, 
затрагиваемые в первоисточнике, отметить цели исследования и указать на новизну данной научной работы в сравнении с другими исследованиями схожей тематики.

Магистров начального этапа обучения необходимо также научить рецензированию и написанию отзывов.

Рецензирование - это один из сложных видов компрессии текста. Этот научный жанр имеет жесткую своеобразную структуру и языковые стандарты-клише. Рецензия представляет собой, с одной стороны, очень сжатый вариант текста-оригинала с изложением позиции автора, a c другой стороны, является критическим анализом, аргументированной оценкой первоисточника, выводов, достоинств языка и стиля автора рецензируемого произведения, выявлением недостатков научного труда. В рецензии также высказываются замечания и пожелания автору труда. Рецензия представляет собой в одно и то же время и текстрассуждение, и текст-размышление, и текст-доказательство. Она может быть опубликована в печатном издании или может быть рецензией на дипломную работу, диссертацию и т.п. Студенту важно научиться самостоятельно писать рецензии, т. к. это способствует формированию научного мышления, умению анализировать, развивает речевую культуру в научной сфере. Содержательная структура рецензии включает следующие компоненты:

a) предмет анализа: указывается тип научной работы (дипломная работа, магистерская диссертация...);

б) актуальность темы: важность затрагиваемых в работе проблем;

в) краткое содержание: осмысление содержания научного труда, значимость для данного и последующих исследований по означенной тематике;

г) оценочная часть: общая оценка научного труда с указанием его новизны, глубины раскрытия темы, аргументированности выводов; указание на недостатки работы делаются в корректной форме;

д) выводы.

Близок рецензии такой жанр компрессии, как отзыв. Отзыв - это критическое описание научной работы, мнения, оценка работы. Его основное назначение - представление научной работы к защите или к изданию. В отличие от рецензии отзыв реализуется через рассуждение-объяснение. Но оба жанра очень близки. Структура отзыва должна включать:

а) вводную (оценочную) часть;

б) описательно-оценочную часть

в) резюме (вывод-оценку).

Как и в рецензии, в отзыве автор критического труда прибегает к клишированным лексико-стилистическим средствам для изложения вводной части (Например: Работа посвящена важной проблеме.., в диссертации рассматриваются актуальные вопросы...); основной описательно-оценочной части (Например: Автор довольно убедительно..., автор убедительно доказывает..., заслуга автора состоит в том, что...); выводов (Например: В заключении делается правильный вывод..., статья представляет интерес...)

Выводы. Итак, нами были рассмотрены различные способы и жанры компрессии научного текста, рассмотрена специфика овладения навыками компрессии текста иностранными студентами, были отмечены этапы работ по трансформации текста-первоисточника во "вторичный текст" в соответствии с заявленной конечной целью, даны были рекомендации по организации и проведению работы со студентами и магистрантами с целью развития навыков разной степени сжатия текста-оригинала, была отмечена важность занятий по обучению студентов компрессии научного текста для развития коммуникативных навыков учащихся-иностранцев.

\section{ЛИТЕРАТУРА}

1. Дерягина, С.И. (2008). Инновационный учебный комплекс по русскому языку для иностранных магистров-журналистов. М.: Изд-во РУДН.96-99.

2. Зарубина, Д.Н., Мельникова, А.Ю. (2017). Развитие навыков компрессии текста у иностранных студентов-нефилологов. Воронеж: Вестник ВГУ. Серия: Лингвистика и Межкультурная коммуникация., №1.136-139 - https://cyberleninka.ru

3. Мусабекова, Н.Ч. (2014). Пособие по научному стилю речи для студентов-иностранцев подготовительного факультета (инженерно-технический профиль обучения). Книга для преподавателя. Баку: Изд-во АзТУ. 62. 